\title{
Age-Related Macular Degeneration
}

National Cancer Institute

\section{Source}

National Cancer Institute. Age-Related Macular Degeneration. NCI Thesaurus. Code C84391.

Age-related loss of vision in the central portion of the retina (macula), secondary to retinal degeneration. 